\title{
The everyday experiences of early childhood caregivers: Challenges in an under-resourced community
}

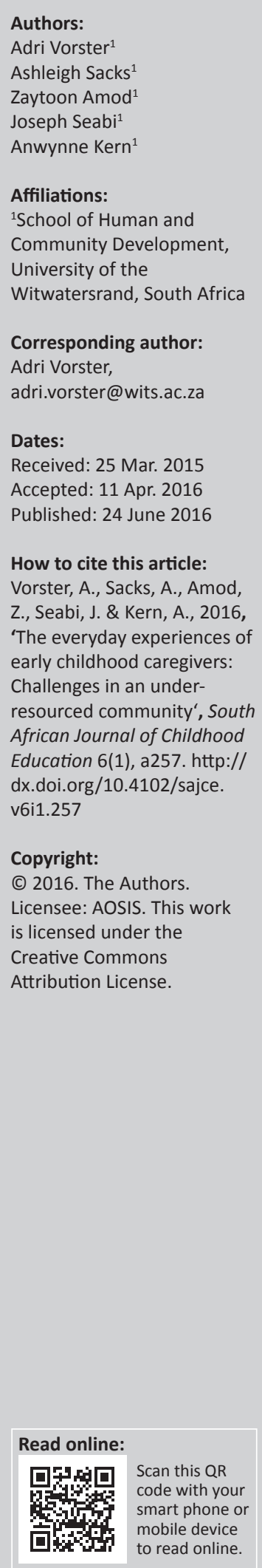

One factor that has been identified to enhance the early development of children is the care provided by caregivers outside the home environment. However, little research has been done in this regard in South Africa, where a significant number of children receive care outside their home environment. The current research study subsequently focused on the experiences of caregivers who work with young children in an under-resourced community. Semi-structured interviews were conducted and revealed the following themes: the responsibility of being a role model; ECD is a place; and challenges for all. Overall, the participants in this sample yielded valuable information that contributes not only to our understanding of the experiences of caregivers in under-resourced communities but the information that also described how some contextual factors could arguably influence the type of care given to young children.

\section{Introduction}

In a recent article, Marmot et al. (2012) speak about the importance of ensuring that all children receive an excellent foundation in life by addressing social inequality through early childhood care and education. They go further to call this a human rights issue. These sentiments are echoed by international and South African authors, state departments and organisations. For instance, an audit report by the Department of Social Development (2014:13) quotes Bathabile Dlamini, Minister of Social Development, in saying that: 'We must ensure that our efforts to expand access to ECD services take into account the need to fight the triple challenge of poverty, inequality and unemployment ...'. Similarly, Atmore, Van Niekerk and Ashley-Cooper (2012a) stress the importance of early childhood care and education in alleviating poverty and thus addressing social inequality. The American Academy of Pediatrics (2012) and Maarman (2009) add to this by saying that in addressing the threats to appropriate early childhood care and education, which endorse social inequality and violate the basic human rights of young children, a country can uphold its democratic ideals.

In South Africa, these ideals are inscribed in our Constitution (Republic of South Africa 1996), as well as in several other legislative documents that pertain to children and more specifically early childhood care; including the National Early Learning Development Standards, the National Programme of Action for Children, the South African Children's Act No. 38 of 2008, the Children's Amendment Act No. 41 of 2007, Education White Paper 5, the National ECD Policy and Programme, and the National Curriculum Framework for Children from Birth to Four Years (Biersteker 2010; UNICEF 2014).

The policies, programmes and legislative documents recognise the importance of inclusive and quality ECD practices by not only viewing it as a basic human right but also by recognising the short- and long-term benefits of ECD learning and growing experiences for children. In this regard, authors such as Excell (2011) and Papatheodorou (2012) recognise that higher quality ECD programmes are designed for the holistic development of children whilst they are in child care and thereafter. This is also the stance of the American Academy of Pediatrics (2012:e232) who indicate that research done in various fields, including 'neuroscience, molecular biology, genomics, developmental psychology, epidemiology, sociology and economics' has developed our understanding of the importance of quality early childhood care and education in the holistic development of children. Conversely, the persistent difficulties that many young children experience can have a detrimental effect on their physical, cognitive, social and mental well-being, even into adulthood. Thus, for these children, who are at risk for developmental and cognitive delays and school failure as a result of growing up within poverty-stricken households (American Academy of Pediatrics 2012; Excell 2011), quality ECD programmes can make a significant difference; not only in the early years of their schooling, but also later in life (Excell 2011). Taking this into consideration, the challenge that the South African education 
system faces is to develop and implement inclusive, quality ECD interventions, especially for children from underresourced communities. These interventions would focus on expanding ECD provisioning and services, whilst addressing the quality of ECD programmes and the unequal distribution of ECD services under the former Apartheid Government (Department of Education 2001).

Biersteker (2010), a leader of the ECD reform movement in the country, has consistently been leading the advocacy for improved preschool care and education. Because access to formal education is no longer an issue in South Africa, the emphasis has now shifted to the quality of foundation phase education as well as the quality of preschool care in statefunded centres as well as in NGO-managed early learning sites (Atmore et al. 2012a). Within developed countries, the focus of ECD interventions and programmes generally falls on formal centre-based provision. In South Africa, as in other subSaharan and developing countries, where political, economic and social factors make formal centre-based ECD programmes problematic, alternative models of ECD provision have become crucial (Van der Vyver 2012a). This appears especially true in under-resourced areas where families struggle to afford early childhood care. Families give preference to home-based programmes due to high unemployment rates amongst family members who can provide care (Ebrahim 2012). Although Education White Paper 5 (Department of Education 2001) and Ebrahim (2012) stress the importance of these alternative models to ECD, Biersteker and Kvalsvig (2007) note that the enabling mechanisms for alternative models of ECD provision remain weak and face many challenges. In this regard, it is noted that the status of ECD in South Africa remains on the periphery; there is limited collaboration amongst stakeholders in providing holistic ECD interventions; and there is a lack of funding and recognition of the caregivers involved in alternative ECD programmes. Ebrahim (2012) proposes that more research is required should we wish for alternative models of ECD provision to remain high on the country's political agenda.

To address the issue of alternative programmes, this research study focused on the lack of recognition that is given to caregivers in alternative ECD programmes. This was done through an exploration of one community-based centre, located in an under-resourced community. The object of the inquiry was the caregivers' experiences. The theoretical lens used for exploring the caregivers' experiences is Vygotsky's social constructivist paradigm. Authors such as Stetsenko and Arievitch (2014:58) highlight that in essence the Vygotskian approach to learning and development is committed to the 'ideals of social justice, equality and social change'. Whilst it emphasises the importance of a child's social context, including aspects of culture, history and politics in his or her development, it also places great value on the role that a child's caregivers can play in optimising development. However, it does not narrowly focus on the manner in which a person is shaped by his or her environment, but also on the manner in which social, cultural and political change can be encouraged by an investment in human capital.
This appeared to be an appropriate theoretical framework, which also correlated with the study's research paradigm; the social constructivist interpretivist paradigm to be discussed later.

Although there appears to be some published research on the importance of ECD within the South African context (Biersteker 2010), as well as on the status it holds within the country and the difficulties it experiences (Atmore, et al. 2012b; Biersteker 2010; Biersteker \& Dawes 2008; Department of Social Development 2014; Van der Vyver 2012b), there seem to be limited research studies on the caregivers who work in community-based ECD centres and facilities. Studies by Grey (2008), Keke (2006) and Van der Vyver (2012a) touched on the important role that caregivers play in the implementation of early childhood development programmes in under-resourced communities. This study focused more specifically on the experiences of caregivers and the challenges they face. Given the emphasis placed on the role of caregivers in ECD centres by organisations such as the Department of Social Development (2014) and the importance of a child's interactions with his or her caregivers and the impact that these can have on the child's development (Schaub 2015; World Health Organization 2004), the present study is not only crucial but also relevant to South Africa.

\section{Early childhood care and education: The foundation for the future}

ECD has received much attention internationally from a number of organisations such as the United Nations Educational, Scientific and Cultural Organisation (UNESCO 2000), as well as the Commission of the European Communities (Commission of the European Communities 2006; Papatheodorou 2012). These international organisations and the initiatives commenced through them, not only gave rise to an increase in research being done on ECD, but also shaped the manner in which ECD is being conceptualised worldwide. As a result, ECD is not viewed as a singular construct, but rather as a holistic concept that focuses on several aspects of a child's development, including their cognitive, social, emotional, moral, spiritual, and physical well-being (American Academy of Pediatrics 2012; Chisholm 2004; Tinajero \& Loizillon 2012). According to Shonkoff, et al. (2011), debates about early childhood care and education often focus on education and the enhancement of children's cognitive skills and later academic progress. However, these authors stress the importance of viewing children in a holistic manner as part of a bigger system. In this manner, early childhood care and education become a vehicle for enhancing the physical, cognitive, mental, social and economic wellbeing of individuals and the societies in which they live. In line with this, ECD is defined in South Africa as: 'an umbrella term that applies to the processes by which children from birth to at least 9 years grow and thrive, physically, mentally, emotionally, spiritually, morally and socially' (Department of Education 2001:9). Accordingly, the aim of ECD interventions 
is to protect and advance the basic rights of all children by actively supporting their full cognitive, emotional, social and physical developmental potential. Taking this into consideration, early childhood care and education within the scope of this paper refer to more than mere schooling and the cognitive development of children. As explained by Shonkoff et al. (2011), they focus on the potential of ECD centres to enhance multiple interdependent dimensions of a child's life; including health and safety, nutrition, emotional well-being, and social competence.

Based on Education White Paper 5 (Department of Education 2001) and other research (Excell 2011; Papatheodorou 2012; Penn 2005; Ramey \& Ramey 2004; Rathus 2006; Tinajero \& Loizillon 2012; Wild 2012), there are a number of compelling arguments for researching and investing in ECD interventions. Firstly, if countries are truly committed to the advancement of the basic rights of children, particularly the right of children to quality, basic education, they are compelled to invest in ECD interventions. Secondly, the first couple of years after birth are crucial in the development of not only a child's cognitive development but also their physical, emotional, social and moral development. Appropriate interventions at this time can support lifelong growth, physical health, development and learning. Thirdly, appropriate ECD interventions can lessen a country's economic burden by supporting increased productivity over a lifetime, a better standard of living when children become adults, lower levels of unemployment and poverty, and less money spent on remedial interventions and health-care. Furthermore, when children are receiving quality care, it alleviates some of the responsibilities of parents, creating opportunities for them to be economically more active, which supports the whole family's income and raises their standard of living. It can also improve a country's status in the global economy as it would be raising the competencies of a nation from early life. Finally, ECD interventions address social, race and gender disparities that currently still divide countries, including South Africa, and can appropriately tackle the inter-generational cycles of poverty, discrimination, disease and violence.

\section{Factors that threaten early childhood care and education in South Africa}

Whilst discussing the benefits of early childhood care and education, the American Academy of Pediatrics (2012) and Shonkoff et al. (2011) also note that the persistent difficulties faced by many young children continuously threaten their lifelong development and potential. Amongst these difficulties are those often associated with developing countries, including poverty, scarcity, violence, malnutrition, discrimination, and inadequate human and physical resources. In South Africa, these threats are rife. For instance, research conducted by the South African Human Rights Commission (SAHRC) and UNICEF (2011) indicated that there are approximately 7 million children who live in the poorest $20.0 \%$ of South African households. Compared to their peers, these children are not only exposed to conditions that pose a threat to their health, but they are also a lot less likely to be enrolled in adequate early childhood development programmes or to complete secondary schooling. Poverty is thus considered one of the most serious threats to early childhood development and care in South Africa.

Berry, Dawes and Biersteker (2013) also noted that the high rates of crime and violence pose a significant risk to the development of South African children. Similarly, the SAHRC and UNICEF (2011) note that a significant number of South African children are being exposed to abuse, neglect and ill-treatment, which can negatively influence all aspects of their development in early childhood. Adding to this, Van der Vyver (2012b) reports that several factors, including limited access to quality ECD interventions, inadequately-trained and qualified teachers, intervention programmes that are of a low quality, and an over-reliance on non-governmental and community-based organisations to provide ECD interventions and services, still threaten the type of care children receive. Another factor that has been identified by authors such as Atmore et al. (2012b) and Tinajero and Loizillon (2012) to enhance the development of children is the quality of care provided by caregivers outside the home environment.

\section{Caregivers and early childhood development}

According to the Department of Education (2001), caregivers who are involved in ECD care and education outside the home environment, including at non-governmental and community centres, can include qualified teachers, or any person involved in the care of children at an ECD centre who are not necessarily formally trained or qualified. It can also be parents who offer their services to the centre on a voluntary basis. For the purpose of this research, the term caregiver was used to define all those involved in the care and support of the children who attend the specific community-based ECD centre.

When taking into consideration that South African children spend a significant amount of their time in the hands of caregivers (Grey 2008), the role of the caregiver in promoting quality ECD care and education in light of the benefits discussed, cannot be underestimated. Van der Vyver (2012b) rightly indicates that it is difficult to define quality care and that people's perceptions of this relies on aspects such as their cultural and religious backgrounds. However, it is recognised that caregivers' perceptions and experiences, which are instrumental in shaping their knowledge and understanding of children, play a key role in the type of care they provide (Kostelnik, Soderman \& Whiren 2007; World Health Organization 2004). The current research study focused on these in an attempt to broaden an understanding of the caregivers in South Africa that offer support and education to children outside their home environment. The following question guided the study, namely: what are caregivers' experiences of ECD in a day-care centre in an under-resourced community? 


\section{Research methods and design Study design}

The present study adopted a qualitative approach. As the study focused on an exploration of caregivers' experiences, it was embedded in a social constructivist interpretivist paradigm (Lipshitz 2012), which acknowledges that people's experiences are socially constructed. Within this paradigm, a phenomenological research design was adopted to give the researchers an opportunity to not only explore a relatively unknown area (Mouton \& Marais 1994; Neuman 2000) but also to describe the context in which the participants' work and live and their experiences within this setting.

\section{Setting}

Although one of the newer townships in South Africa, the setting in which the caregivers live and work is also one of the poorest (Cross 2014). As such it stands in stark contrast to the wealthy urban settlements which surround it, and is a spatial reminder of the inequality that still exists in the country. Established in 1995, it was supposed to be a temporary home for groups of people relocated from other informal settlements. However, it quickly developed and is estimated to host close to 200000 residents, of which there are slightly more males (54.5\%) than females (45.5\%). As far as the racial structure of the community is concerned, 98.0\% are Black Africans, with a significant number of immigrants from across the world. In recent years, the community has seen many violent xenophobic attacks, in addition to the recurring crime and violence that appear to weigh it down (Cross 2014; Mahajan 2014; Statistics South Africa 2011).

There appear to be a number of factors that contribute to the economic hardships experienced within this setting. Although it is considered a young community and approximately $77.4 \%$ falls within the 'working age' group, very few residents appear to have access to a stable income. Unemployment rates are similar to other South African townships, sitting at approximately $30.0 \%$ which is considered high. Adding to this, the general income in the community appears low, with the majority of residents earning between R19 601 and R38 200 annually. Very few residents have completed formal schooling, and in general the educational outcomes of this community are considered poor (Mahajan 2014; Statistics South Africa 2011).
Cross (2014) notes that there are close to 50 ECD centres in this particular community. The one in which the caregivers work is an NGO, which relies on funding from external sources to sustain its work. It accommodates approximately 250 children from the community. It aims to provide the children with a solid foundation before they enter formal schooling, as well as protect them from the difficulties associated with the context in which they are growing up.

\section{Study population and sampling strategy}

Non-probability purposive sampling was used in the selection of eight caregivers using the following inclusion criteria, namely, the caregivers selected had to work with children below the age of 7 years; had to be permanently based at the selected day-care facility and had to live in the community where the day-care centre is situated as this provided more in depth understanding about the setting. Table 1 provides a summary of the participants. In addition, based on our conceptualisation of early childhood care and education, outlined earlier, the centre was chosen as it not only provides schooling to young children but also nutritional meals and health-care services. It is furthermore based in an underresourced community, struggling with the difficulties so often found in these communities in South Africa.

\section{Data collection}

In order to explore and describe the caregivers' experiences, semi-structured interviews were conducted. Although these interviews gave the researchers an opportunity to explore the caregivers' experiences from their perspectives and explore a relatively unknown area of research, it should be noted that these were done in English, which none of the participants spoke as a first language.

\section{Data analysis}

The data were analysed using thematic content analysis (Braun \& Clarke 2006). According to this method of data analyses, specific themes were identified once the interviews had been transcribed verbatim. These themes included the responsibility of being a role model; ECD is a place; and challenges for all.

\section{Ethical considerations}

Before the research study was undertaken, ethical clearance was obtained from the University of the Witwatersrand.

TABLE 1: Participants' demographics.

\begin{tabular}{|c|c|c|c|c|c|}
\hline Pseudonym & Position & $\begin{array}{l}\text { Age of children with whom } \\
\text { participant works }\end{array}$ & Race & Highest education level & Time at centre \\
\hline Participant 1 & Teacher & $5-6$ years & Black people & NQF Level 5 Diploma & 8 years \\
\hline Participant 2 & Teacher & $1-6$ years & Black people & NQF Level 5 Diploma & 8 years \\
\hline Participant 3 & Assistant Teacher & $3-4$ years & Black people & NQF Level 4 Matric & 11 months \\
\hline Participant 4 & Assistant Teacher & $4-5$ years & Black people & NQF Level 4 Matric & 1 year \\
\hline Participant 5 & Assistant Teacher & 3 years & Black people & NQF Level 4 Matric & 3 months \\
\hline Participant 6 & Teacher & $4-5$ years & Black people & NQF Level 4 Matric And Further Courses & 3 years \\
\hline Participant 7 & Teacher & $4-5$ years & Black people & NQF Level 4 Matric And Further Courses & 3 years \\
\hline Participant 8 & Assistant Teacher & 3 years & Black people & NQF Level 4 Matric & 11 months \\
\hline
\end{tabular}

Source: Authors' own work 
Thereafter, written and informed consent to conduct the study was obtained from the management of the ECD centre, the principal and finally the participants. All of these stakeholders were informed about the nature and purpose of the study, the fact that participation was voluntary, that any participant could withdraw from the study at any time and refuse to answer any questions he or she did not feel comfortable with, and that confidentiality and anonymity would be maintained in the publication report and any additional publications that might arise from it. Participants were also advised that all interviews would be audiorecorded for analysis purposes and they were asked to sign an additional consent form in this regard. Interviews were conducted at a time convenient for the participants, so that their work was not negatively impacted on in any manner.

\section{Findings and discussion}

In exploring the caregivers' experiences working at an ECD centre in an under-resourced community, three central themes emerged: the responsibility of being a role model; ECD is a place; and challenges for all.

\section{Theme 1: The responsibility of being a role model}

Within a community inundated by economic hardships and other related difficulties, including the absence of biological parents, the participants of this study placed quite a bit of emphasis on the importance of their position in the lives of the children they take care of. One participant in particular viewed herself not only as a caregiver but more importantly as a role model to the children in her care:

'I am the role model, but most people they don't understand and if like ah ... ah some of the child did something wrong and we as a teacher decide to beat that child in front of the other kids those kids that are watching tomorrow they will be something who is doing something wrong to them, then again they will reference you and beat that child. So you like have to teach them when there is a problem you sit down and talk about the problem and find a solution.'

When taking into consideration the context from which the children at the centre come, the participants' understanding of their position as role models becomes noteworthy. A significant number of children from under-resourced communities in South Africa are not raised by their biological parents (SAHRC \& UNICEF 2011) and often do not have appropriate role models. Within this community, $28.6 \%$ of households are female headed, indicating the absence of at least one biological parent.

Further to their position as role models, some participants also noted that they are expected to not only develop the children scholastically but also emotionally, physically and socially. This is in line with the Department of Education's (2001) conceptualisation that ECD is a vast concept. However, in a context where there are limited resources, and the basic rights of children are not always met (SAHRC \& UNICEF 2011), these caregivers do not necessarily have other avenues to support them in taking care of the children holistically. Subsequently, as one participant rightly observed, the responsibility to assist the children in their care beyond what is covered in the academic curriculum, rests on their shoulders:

'I just teach them about everything that is expected out of me in the class. Different learning areas, classroom layout, identifying children's problems especially abuse, and especially maybe physical and sexual abuse. And so I am expected to be able to identify such children, and um I do, with the education that I got so I am able to identify such children.'

Two groups emerged from the participants of this study: teachers and teaching assistants. The teachers generally had further educational training such as a diploma or other courses and they had more experience in the field of ECD. However, all participants agreed that it is important for ECD caregivers to be appropriately qualified and noted the importance of further training and education on the care that they provide. Literature also cites the importance of education for proper care of children (Colker 2008; Department of Social Development 2014; Van der Vyver 2012a). However, as noted by one of the participants:

'You can have papers and a lot of degrees and diplomas, but if don't have the right stuff, you cannot manage to work with children and that would make you a bad teacher.'

Taking this statement into consideration, research conducted by Colker (2008) found that quality care is most often offered by individuals who possess certain characteristics or qualities that predispose them to working with children. Likewise, the participants of this study also identified certain qualities that they considered important and necessary for ECD caregivers and teachers. The first of these was passion, which were identified by most of the participants in this study as an integral part of working with the children who attend the ECD centre. Similarly, the 43 ECD practitioners' surveyed by Colker (2008) also reported passion to be the number one characteristic necessary for quality caregiving in the early years; describing passion as not just enthusiasm but more of a driving force.

The second was creativity, with the findings of this study highlighting that the application of creativity may differ owing to environmental influences. Being in an underresourced community, the participants contend with a severe lack of resources resulting from financial scarcity. In light of this, the participants viewed creativity as an ability to solve problems and to compensate for material scarcity. Finally, many of the participants explained that there is much value in understanding the child and being on the child's level. In their opinion, this can be achieved through listening, effective communication and sensitivity towards the needs of the children they interact with. In this regard, a number of classical research studies (Ainsworth 1982; Baumrind 1971; Bowlby 1969; Winnicott 1965) also cite the importance of being responsive and understanding of a child's needs. 


\section{Theme 2: A place}

Most participants found it difficult to convey their understanding of ECD verbally, which might be due to the fact that a significant number of them perceived it to be a physical location. Given the community where the children grow up and the high crime rate and related mortality rates, one participant in particular remarked:

'I think it's a safe place for kids ... yes ... it's a good place to take care of kids ... parents are happy ... because it is a safe environment.'

Some of the participants, especially those with additional training and more experience in the field, elaborated on the concept of ECD and in line with the definition provided by the Department of Education (2001) stressed the importance of early care and education in the holistic development of children. However, the findings offered new insight as to why ECD is perceived as important in the eyes of the caregivers in this under-resourced community. Although a number of domains of development were noted by the participants, the one that was emphasised as being the most important was the social development of the children. The participants cited social interaction, manners, sharing and respect for others as some of the most important reasons for adequate child care and education at a young age.

Research in the field of ECD has indeed stipulated that ECD contributes to the social development of an individual (Barnett 2004; Kington, Gates \& Sammons 2013). Research by Phal and Barrett (2007) expands by adding that not only is ECD important for social development, but that social development is an imperative part of adjustment to formal schooling. The findings of the present study thus corroborate this, however, the participants' cultural background, rather than their understanding of ECD, might more aptly account for them placing a high level of importance on socialisation. The participants are all African and thus possibly influenced by African cultural and traditional norms. In general, African cultures in South Africa place a high importance on community spirit and communal interaction; however, the idea of collectivism as a way of life is not specific to African traditions. Similar beliefs exist in areas of East Asia, where education is seen to be a vehicle of socialisation and a means of equipping children with the skills necessary for partaking in communal life (Cheng 1998). Given the views expressed by the participants of this study, it would appear that in their opinion adequate care and education at a young age is also seen as way of equipping children to participate in their community and the broader social context.

Whilst taking the above into consideration, some participants also identified school readiness and future educational prospects as important. Interestingly, only participants that had some further education and training identified these aspects as important. The views of these participants concur with current literature that explains that the early years lay the foundation for constructive growth throughout the life cycle and lifelong prosperity in all domains of development
(Excell 2011; Papatheodorou 2012). However, in contrast to the importance placed on social development, the identification of school readiness as an important reason for adequate child care and education at a young age by some participants in this study might be as a result of these participants' further training and their potential exposure to a broader conception of education.

\section{Theme 3: Challenges for all}

Through the lens of social constructivism, perceptions, thoughts, ideas and beliefs are partially shaped through experiences and it became evident that the barriers encountered on a daily basis by the participants in this work setting shaped many of their experiences. These barriers fell into three broad categories: the first included challenges experienced by caregivers directly. The second included challenges experienced by the children in the ECD centre. Related to these two, the third included challenges experienced by the wider community where the centre is situated.

As far as the challenges experienced by the teachers are concerned, several participants identified a lack of resources as a significant inhibitor to quality care and education. As noted by one of the participants: 'We need more resources. We are struggling.'

However, it became evident that resources were perceived differently from one participant to the next, some listing toys and equipment, whilst others stationery and notebooks and still others the lack of qualified teachers. In the case of this particular ECD centre, which is an NGO that relies on external funding, the participants noted that they cannot always rely on getting the necessary resources that each child needed to progress:

'We have to depend on donors. And you don't know when a donor is going to come and say, 'You know what you really need? Lego blocks. Here are some Lego blocks'. It can take the whole year for me to get Lego blocks; it can take the whole year for the babies to get teddy bears. You know, such things. So that is a big challenge.'

In reporting on an audit by the Department of Social Development (2014), it is suggested that a lack of resources is prevalent in ECD centres in South Africa, particularly in resource-poor communities. Similar research by Keke (2006) corroborated the prevalence of scarcity when it comes to educational resources; particularly for ECD centres. Ramey and Ramey (2004) investigated the impact of quality preschool environments on children's well-being and found that lack of resources, such as equipment, inexperienced caregivers and poor planning correlates with lower gains in cognitive and emotional domains.

Despite the identified scarcity in resources, Biersteker (2001) postulates that the single most important resource in any facility and even any country is the teacher or caregiver. Since this is the case, Colker (2008) explains that the well-being of teachers or caregivers is a vital consideration in offering 
quality care to children. The participants in the current study identified number of factors that may hinder their physical, psychological and emotional well-being; the most prevalent being that they do not get any holidays through the course of the year. According to Ransford et al. (2009), one of the most prevalent complaints in teachers is stress and burnout; with holiday periods allowing them an opportunity to recharge mentally and physically. However, in the case of an NGO this luxury does not exist and as the children who attend the centre often have nowhere else to stay, the caregivers ensure that they are always available.

To compound the situation further, the participants explain that they find the long working hours to be particularly challenging. Although the centre is only required to operate for $9 \mathrm{~h}$ daily, some children are just left at the centre after hours. This was identified as a major concern, indicating that it affects participants' well-being and leads to a negative experience of their position as caregivers. This in turn affects their ability to offer quality childhood experience and also impacts on their personal lives and their relationships. Furthermore, some of the participants explained that their long working hours have also led to discord with the management of the organisation, as they are not perceived to be supportive in this regard:

'The challenges that we face here is only the challenge of that one of fetching the children late. Some parents are ignoring it and leave the children until very late.'

Thus, the long working hours to which the caregivers are exposed and the lack of rest affect their levels of job satisfaction, as well as psychological and emotional wellbeing, which according to Colker (2008), influences caregiverchild interactions. The Department of Social Development (2014) stated that according to information gathered during its audit, caregivers in ECD centres across South Africa work an average of $9 \mathrm{~h}$ per day. This therefore seems to be a very prevalent situation to which the parents of the children are contributing.

In addition to the long working hours, many participants cited financial concerns as an on-going challenge affecting their well-being and job satisfaction. The participants explained that the financial ramifications of working in an under-resourced ECD centre for a very small salary adds to the stress of the long hours and lack of rest, which in turn negatively affect the care they provide:

'Let's just say our salaries are a challenge because sometimes you can do more, more, more; expecting more, but maybe if I got this amount it would be much better, because the more you are not happy with the salary, the more you will be happy with the kids.'

This corresponds with research (Biersteker \& Dawes 2008), which explains that given the past neglect of ECD in South Africa, the field is unattractive to potential candidates as it involves long hours and poor pay. To complicate matters further, the participants also noted that the children in their care face many challenges on a daily basis. In this regard, poverty and abuse were noted as major concerns.
Poverty is a continuous challenge in under-resourced communities. The implications of poverty are far reaching and complex, as poverty affects individuals in different ways. Poverty and related themes were identified by all participants, in one way or another, as being a major barrier not only to the provision of ECD but also to the children's physical, cognitive and emotional well-being. In addition to poverty, child abuse was also seen as a major concern by the participants of this study. According to the World Health Organization (2010), a high incidence of abuse is associated with living in conditions of poverty. The participants of this study identified abuse as being prevalent in the centre and noted that as a result of this occurring in their immediate home environment, children are often left in the care of their grandparents or other nonrelated caregivers, which can also have detrimental effects.

Poverty and abuse experienced by the children who attend the ECD centre appears to be related to the community in which they are growing up. A recent report by Statistics South Africa (2013) indicates that many black South African children contend with living conditions characterised by scarcity and hardship. There is no place, where this is more evident than in townships and under-resourced communities, which affects the quality of care the caregivers are able to offer as living in a high-risk area is associated with higher levels of stress according to Van Der Vyver (2012b). Furthermore, the social situation means that ECD is often not high on the agenda for many parents, as basic survival needs take precedence over less pressing matters.

Despite all the difficulties noted, it is important to note that the participants also mentioned the positive influence of the centre and the NGO that supports it, on the early development of children and the care they provide to these children:

[The organisation] has changed people's lives, in different ways because they are developing a community in a way that they are giving kids who are, say, starving at home they are giving them food. Those are the positive things.

\section{Conclusion}

The past decades bear witness, globally and locally, to a shift in worldviews on children and their development. Increasing emphasis is being placed on the importance of the early years, both for individual growth and adjustment and for the development of sustainable societies free of social inequalities. In South Africa, the need to align with global trends in ECD and education is imperative in fighting the lasting consequences of apartheid. Research has found that only quality interventions and caregiving dictate positive outcomes necessary for change and that caregivers themselves most often shape quality care. In turn, caregivers are shaped by their perceptions and experiences of their environment and work contexts.

This research began with the aim to explore the experiences of caregivers concerning early childhood development and education; specifically as it manifests in a resource-poor community. Overall, the participants in this sample yielded 
information that contributes not only to our understanding of the experiences of caregivers in under-resourced communities with regards to early development and education but also to the influence of contextual factors on the care that is provided to children. However, whilst taking this into consideration, it is also important to reflect on the limitations of this study. Firstly, it is important to acknowledge that a bigger and more diverse sample would have allowed for an even deeper understanding of the caregivers' experiences. Secondly, the only members of the centre who were interviewed were the caregivers directly involved in the ECD centre. Thus, no other members of this NGO were interviewed and although the focus of this study fell on the experiences of these caregivers, additional interviews and document analysis could have assisted in corroborating the findings of the study and shed more light on the caregivers' experiences. Thirdly, all the interviews were conducted in English. All eight participants spoke English as a second language and hence struggled to express their opinions and ideas in this medium, which may have shaped their responses to the interview questions. Finally, it is important to note that some caregivers may have been somewhat weary because of recent retrenchments in the organisation and thus may have answered questions in what they perceived to be an acceptable and knowledgeable manner. Despite these, this study gave a voice to the struggles of caregivers from underresourced areas and shed light on the challenges experienced by caregivers in South Africa in providing quality care to children at a young age.

\section{Acknowledgements Competing interests}

The authors declare that they have no financial or personal relationships which may have inappropriately influenced them in writing this article.

\section{Authors' contributions}

A.V. made substantial contributions to the conceptualization of the study, supervised the implementation of the study and its write-up, assisted in data analysis, and drafted and revised the manuscript. A.S. made substantial contributions to conceptualisation of the study, performed the literature search, designed data collection instruments, collected data for the study, cleaned and analysed the data, and assisted in drafting and revising the manuscript. Z.A. participated in the design and coordination of the study and critically revised the manuscript for important intellectual content. J.S. participated in the design and coordination of the study and critically revised the manuscript for important intellectual content. A.K. participated in the design and coordination of the study and critically revised the manuscript for important intellectual content. All authors read and approved the final manuscript.

\section{References}

Ainsworth, M.D., 1982, 'Attachment: Retrospect and prospect', in C.M. Parkes \& J. Stevenson-Hinde (eds.), The place of attachment in human behavior, pp. 3-30. Basic Books, New York, NY.
American Academy of Pediatrics, 2012, 'The lifelong effects of early childhood adversity and toxic stress', Pediatrics 129(1), e232-e246. http://dx.doi.org/0.1542/ peds.2011-2663

Atmore, E., Van Niekerk, L. \& Ashley-Cooper, M.A., 2012a, Early childhood education: The difference between policy and reality, The Centre for Early Childhood Development, Cape Town, South Africa.

Atmore, E., Van Niekerk, L. \& Ashley-Cooper, M.A., 2012b, 'Challenges facing the early childhood development sector in South Africa', South African Journal of Childhood Education 2, 120-139.

Barnett, W.S., 2004, Child care and its impact on children 2-5 years of age. Commenting McCartney, Peisner-Feinberg, and Ahnert and Lamb, Encyclopedia on Early Childhood Development, viewed 25 September 2013, from http://www. childencyclopedia.com/Pages/PDF/BarnettANGxp2.pdf

Baumrind, D., 1971, 'Current patterns of parental authority', Developmental Psychology 4(1, pt.2), 1-103. http://dx.doi.org/10.1037/h0030372

Berry, L., Dawes, A. \& Biersteker, L., 2013, 'Getting the basics right: An essential package of service and support for ECD', in L. Berry, L. Biersteker, A. Dawes, L. Lake \& C. Smith (eds.), South African Child Gauge 2013, pp. 26-33, Children's Institute, University of Cape Town, Cape Town, South Africa.

Biersteker, L., 2001, Early childhood development: A review of public policy and funding, Children's Budget Project: IDASA, Cape Town, South Africa.

Biersteker, L., 2010, Scaling-up early child development in South Africa: Introducing a reception year (Grade $R$ ) for children aged five years as the first year of schooling, Wolfensohn Institute for Development at Brookings, Washington, DC.

Biersteker, L. \& Dawes, A., 2008, 'Early childhood development', in A. Kraak \& K. Press (eds.), Human resources development review 2008: Education, employment and skills in South Africa, pp. 185-205, HSRC Press, Cape Town, South Africa.

Biersteker, L. \& Kvalsvig, J., 2007, 'Early childhood development and the home-care environment in the pre-school years', in A. Dawes, R. Bray \& A. Van der Merwe (eds.), Monitoring child well-being: A South African rights-based approach, pp. 159-189, HSRC Press, Cape Town, South Africa.

Bowlby, J., 1969, Attachment and loss, vol.1: Attachment, Basic Books, New York, NY.

Braun, V. \& Clarke, V., 2006, 'Using thematic analysis in psychology', Qualitative Research in Psychology 3,7-101. http://dx.doi.org/10.1191/1478088706qp063oa

Cheng, K., 1998, 'Can education values be borrowed? Looking into cultural differences', Peabody Journal of Education 73(2), 11-30. http://dx.doi.org/10.1207/s15327930 pje7302_1

Chisholm, L., 2004, Changing class: Education and social change in post-apartheid South Africa, HSRC Press, Cape Town, South Africa.

Colker, L.J., 2008, 'Twelve characteristics of effective early childhood teachers', Young Children 63(2), 68-73.

Commission of the European Communities, 2006, Communication from the Commission to the Council and to the European Parliament. Efficiency and equity in European education and training systems, viewed 25 September 2013, from http://eur-lex. europa.eu/LexUriServ/LexUriServ.do?uri =COM:2006:0481:FIN:EN:PDF

Cross, C., 2014, 'Qualitative assessment of the Diepsloot community' in S. Mahajan (ed.), Economics of South African townships, pp. 143-178, World Bank, Washington, DC.

Department of Education, 2001, Education White Paper 5 on early childhood education. Meeting the challenge of early childhood development in South Africa, Department of Education, Pretoria, South Africa.

Department of Social Development, 2014, Audit on early childhood development (ECD) centres: National report, Department of Social Development, Pretoria, South Africa.

Ebrahim, H.B., 2012, 'Emerging models for early childhood development from birth to four in South Africa', in T. Papatheodorou (ed.), International debates on early childhood practices and policies, pp. 62-71, Routledge, New York, NY.

Excell, L.A., 2011, Grade R' teachers' perceptions of early childhood development and how these impact on classroom practice (Doctoral dissertation), University of the Witwatersrand, Johannesburg, South Africa.

Grey, M.J., 2008, 'An investigation of the programmes and equipment used by caregivers and day mothers for the group 0-36 months in Limpopo Province, South Africa', (Unpublished Master's thesis), University of the Witswatersrand, Johannesburg, South Africa.

Keke, X., 2006, 'Partial care facilities and early childhood development in cato manor', (Unpublished Master's thesis), University of Kwazulu-Natal, Durban, South Africa.

Kington, A., Gates, P. \& Sammons, P., 2013, 'Development of social relationships, interactions and behaviours in early education settings', Journal of Early Childhood Research 11(3), 292-311. http://dx.doi.org/10.1177/1476718X13492936

Kostelnik, M.J., Soderman, A.K. \& Whiren, A., 2007, Developmentally appropriate curriculum: Best practices in early childhood education, 4th ed., Pearson Education, Upper Saddle River, NJ.

Lipshitz, S.J., 2012, 'The educational and psychological role that grandparents play when raising vulnerable learners', (Unpublished master's dissertation), University of Johannesburg, Johannesburg, South Africa.

Maarman, R., 2009, 'Manifestations of "capabilities poverty" with learners attending informal settlement schools', South African Journal of Education 29, 317-331.

Mahajan, S., 2014, 'Overview', in S. Mahajan (ed.), Economics of South African townships, pp. 1-30, The World Bank, Washington, DC. 
Marmot, M., Allen, J., Bell, R., Bloomer, E. \& Goldblatt, P., 2012, 'WHO European review of social determinants of health and health divide', Lancet 380, 1011-1029. http://dx.doi.org/10.1016/S0140-6736(12)61228-8

Mouton, S. \& Marais, H.C., 1994, Basic concepts in the methodology of the socia sciences, HSRC Press, Pretoria, South Africa. http://dx.doi.org/10.1375/ajgc.17.1.8

Neuman, W.L., 2000, Social research methods: Qualitative and quantitative approaches, 4th ed., Pearson, Whitewater, WI.

Papatheodorou, T., 2012, 'Introduction: Early childhood policies and practices', in T. Papatheodorou (ed.), International debates on early childhood practices and policies, pp. 1-14, Routledge, New York, NY.

Penn, H., 2005, Unequal childhoods young children's lives in poor countries, Routledge, New York, NY.

Phal, K.M. \& Barrett, P., 2007, 'The development of social-emotional competence in preschool-aged children: An introduction to the fun FRIENDS program', Australian Journal of Guidance \& Counselling 17(1), 81-90. http://dx.doi.org/10.1375/ajgc.17.1.8

Ramey, C. \& Ramey, S., 2004, 'Early learning and school readiness: Can early interventions make a difference?', Marrill-Palmer Quarterly 50(4), 471-491. http://dx.doi.org/10.1353/mpq.2004.0034

Ransford, C.R., Greenberg, M.T., Domitrovich, C.E., Small, M. \& Jacobson, L., 2009, 'The role of teachers' psychological experiences and perceptions of curriculum supports on the implementation of a social and emotional learning curriculum', supports on the implementation of a soci
School Psychology Review 38(4), 510-532.

Rathus, S.A., 2006, Childhood and adolescence voyages in development, Thomson Wadsworth, Belmont, NY.

Republic of South Africa, 1996, Constitution of the Republic of South Africa. No. 108 of 1996, Government Printer, Pretoria, South Africa.

Schaub, M., 2015, 'Is there a home advantage in school readiness for young children? Trends in parent engagement in cognitive activities with young children, 1991-2001 Journal of Early Childhood Research 13(1), 47-63. http://dx.doi.org/10.1177/ $1476718 \times 12468122$

Shonkoff, J.P., Richter, L., Van der Gaag, J. \& Bhutta, A., 2011, 'An integrated scientific framework for child survival and early childhood development', Pediatrics 129(2), e460-472. http://dx.doi.org/10.1542/peds.2011-0366.

South African Human Rights Commission \& UNICEF, 2011, South Africa's children - A review of equity and child rights, viewed 2 March 2011, from http://www. review of equity and child rights, viewed 2 March 2011, from
health-e.org.za/uploaded/fe94f5f04583baf7585f6701946b5ac9.pdf
Statistics South Africa, 2011, My settlement: Diepsloot, viewed 3 April 2016, from http://www.statssa.gov.za/?page_id=4286\&id=1294

Statistics South Africa, 2013, South Africa's young children, their family and home environment, 2012, Statistics South Africa, Pretoria, South Africa.

Stetsenko, A. \& Arievitch, I.M., 2014, 'Vygotskian collaborative project of social transformation: History, politics, and practice in knowledge construction', in A. Blunden (ed.), Collaborative projects: An interdisciplinary study, pp. 217-238, Brill, Leiden, The Netherlands.

Tinajero, A.R. \& Loizillon, A., 2012, Review of care, education and child development indicators in early childhood. Fontenoy, France: United Nations Educational, Scientific and Cultural Organization (UNESCO), viewed 25 September 2013, from http://unesdoc.unesco.org/images/0021/002157/215729e.pdf

UNICEF, 2014, Early childhood development knowledge building seminar 2014: ECD@20, UNICEF, Pretoria, South Africa.

United Nations Educational Scientific and Cultural Organisation, 2000, World Education Forum, The Dakar Framework for Action. Education for all: Meeting our collective commitments. Adopted by the World Education Forum, Dakar, Senegal, 26-28 April 2000, viewed 25 September 2013, from http://unesdoc.unesco.org/ images/0012/001211/121147e.pdf

Van der Vyver, S., 2012a, 'An early childhood development programme in a rural settlement community', (Unpublished Master's thesis), University of Johannesburg, Johannesburg, South Africa.

Van der Vyver, S., 2012b, 'Methodology and theory in a rural ECD research project: Capturing Mogwase in 'becoming', South African Journal of Childhood Education 2(1), 141-159.

Wild, L., 2012, 'Infancy', in J. Hardman (ed.), Child and adolescent development: A South African socio-cultural perspective, pp. 91-132, Oxford University Press, Cape Town, South Africa.

Winnicott, D.W., 1965, 'The theory of the parent-infant relationship', in D.W. Winnicott (ed.), The maturational processes and the facilitating environment, pp. 37-55, International Universities press, New York, NY.

World Health Organization, 2004, The importance of caregiver-child interactions for the survival and healthy development of young children: A review, World Health Organization Department of Child and Adolescent Health and Development, Geneva, Switzerland.

World Health Organization, 2010, Violence prevention: The evidence, World Health Organization, Geneva, Switzerland. 